\title{
DISKURSUS MUSLIM ABAD PERTENGAHAN TENTANG AGAMA DAN SEKTE
}

\author{
Anjar Nugroho \\ Universitas Muhammadiyah Purwokerto, Indonesia \\ anjar@ump.ac.id
}

\begin{abstract}
The article observes the features of Medieval Muslims treatises on religions and sects. A number of Muslim scholars penned more than a few works relating to religious and intercultural studies. Yet, the majority of scholars had a similar focus: either the "biblical religions" or "Muslim heresies", while others went further with a deep elaboration about the religious traditions of the Hind. In discussing biblical religions and Muslim heresies, the common trend, technique, and method employed by Muslim writers in medieval era were mostly polemical and apologetic. Moreover, the types of information obtained by medieval Muslim scholars, according to the writer, were typically regional and cross-cultural studies that occasionally cover discussions pertaining to religious ideas or religious communities. In line with Muslim political and cultural expansion, the observations of Muslim travelers and writers at the time were not restricted to societies, religions and cultures of the Arab peninsula and Persia, but also turned upon the Hind and even China. At least, three different categories of information can further be seen within their works: some Muslim scholars emphasized their appreciation of cultural studies, some concentrated on their eyewitness accounts concerning a certain region and its geographical information, and others provided encyclopedic works and digests.
\end{abstract}

Keywords: Religious Studies, Heresy, Heresiography, and Medieval Islam.

\begin{abstract}
Abstrak
Artikel ini mengkaji ciri-ciri risalah Muslim Abad Pertengahan tentang agama dan sekte. Sejumlah ilmuwan Muslim menulis lebih dari beberapa karya yang berkaitan dengan studi agama dan antar budaya. Namun, sebagian besar ilmuwan memiliki fokus yang sama: baik "agama Al-kitab” atau "ajaran sesat Muslim”, sementara yang lain melangkah lebih jauh dengan penjelasan mendalam tentang tradisi keagamaan Hind. Dalam membahas agamaagama alkitabiah dan ajaran sesat Muslim, kecenderungan umum, teknik, dan metode yang digunakan oleh para penulis Muslim di era abad pertengahan kebanyakan bersifat polemik dan apologetis. Selain itu, jenis informasi yang diperoleh ilmuwan abad pertengahan Muslim, menurut penulis, biasanya merupakan studi regional dan lintas budaya yang kadang-kadang mencakup diskusi mengenai gagasan keagamaan atau komunitas religius. Sejalan dengan ekspansi politik dan budaya Muslim, pengamatan para pengamat Muslim dan penulis pada saat itu tidak terbatas pada masyarakat, agama dan budaya di semenanjung Arab dan Persia, namun juga menghidupkan Hind dan bahkan China. Paling tidak, tiga kategori informasi yang
\end{abstract}


berbeda dapat dilihat lebih jauh dalam karya mereka: beberapa ilmuwan Muslim menekankan apresiasi mereka terhadap studi budaya, beberapa terkonsentrasi pada laporan saksi mata mereka mengenai wilayah tertentu dan informasi geografinya, dan yang lainnya menyediakan karya ensiklopedi dan intisari.

Kata Kunci: Studi Agama, Bid'ah, Heresiografi, dan Islam Abad Pertengahan.

\section{Pendahuluan}

Sejarah pemikiran adalah sejarah para pemikir, begitu tulis Luthfi Assyaukani, ${ }^{1}$ sejarah kaum elit yang dengan kepandaiannya mampu mengabstraksikan fenomena sosial dan gejala lainnya ke dalam bahasa intelektual dan ilmiah. Pemikiran Islam dalam sejarahnya terbagi dalam tiga era, yaitu era klasik, pertengahan, dan modern. Masing-masing era membentuk tipologi tertentu sejalan dengan perkembangan sosial politik yang melingkupi sejarah itu.

Studi agama-agama dan heresiografi dalam sejarah intelektual Muslim menemukan momentum utamanya pada Abad Pertengahan Islam ketika karya-karya besar di bidang ini mulai dirintis dan dikembangkan oleh sarjana, teolog, dan heresiograp Muslim. Abû Rayhân al-Bîrûnî (w. 1048), Ibn Hazm (w. 1064), dan 'Abdul Karîm al-Syahrastânî (w. 1153) adalah tiga nama yang cukup dikenal di bidang ini. Ketiganya bahkan dianggap sebagai tokoh utama dalam bidang kajian agama-agama dan heresiografi yang merepresentasikan tipologi generasi sarjana Muslim di tiga wilayah berbeda. Al-Bîrûnî merupakan sarjana kenamaan asal Khwarism (Uzbekistan) yang menelurkan banyak karya di bidang sains, dan pada saat yang sama, ia tertarik untuk menulis peradaban dunia yang berkaitan dengan agama dan filsafat. Ibn $\underline{\text { Hazm}}$, di sisi lain, merepresentasikan satu "generasi emas" dari geliat Islam di Cordoba (Andalusia), di mana karya-karyanya dalam bidang hukum, politik, sastra, dan agama ikut mewarnai karya-

'Luthfi Assyaukanie, "Tipologi dan Wacana Pemikiran Arab Kontemporer," dalam Jurnal Pemikiran Islam Paramadina I, no. 1 (1998): 58-59. karya besar abad pertengahan Islam. Dinamika relasi Muslim-Kristen di Cordoba yang telah mewariskan cara pandang kritisnya terhadap tradisi Yahudi dan Kristen merupakan sisi lain dari karakteristik karyanya. Sementara itu, al-Syahrastânî, filsuf dan sekaligus teolog besar 'Asy'ariyah pasca al-Ghazâlî adalah orang Syahristân (Persia) yang melengkapi dan "menyempurnakan" model analisis heresiografi yang telah ditulis sarjana Muslim sebelumnya.

Kajian tentang pemikiran para tokoh Muslim era pertengahan ini menjadi menarik karena karya-karya mereka telah mendapat "pengakuan" dan "pengukuhan" dari para sarjana dan Islamisis Barat. Terhadap luasnya ruang lingkup agama-agama dan detailnya erudisi yang terdapat dalam beberapa karya alBîrûnî, Arthur Jeffery, umpamanya, menyatakan bahwa kontribusi al-Bîrûnî dalam bidang studi agama dengan meneguhkan prinsipprinsip ilmiah yang cermat dan teliti, seperti keparipurnaan (completeness), ketepatan (accuracy), dan sikap jujur (unbiased treatment) adalah sangat langka di zamannya dan dapat dikatakan sangat unik dalam sejarah keyakinan keagamaan yang dianutnya.

If Comparative Religion means the study of Religion by the same scientific method as is used in Comparative Philology, viz. the assembling of facts about the beliefs and practices of various religious groups, arranging them, classifying them, comparing them with one another and with the beliefs and practices of one's own religion, in order to arrive at a better understanding of the significance of religion, then this branch of study had already had a long history in the 
area of al-Bîrûn's life work. ${ }^{2}$

Theodor Pulcini dalam mendeskripsikan Ibn Hazm yang didasarkan pada pernyataan Asín Palacios, Islamisis Spanyol kenamaan di awal abad ke-20 yang juga banyak menerjemahkan beberapa karya Ibn Hazm, menyatakan:

The breadth of the contribution made by Ibn Hazm to Arabic Islamic culture is indicated by the multiplicity of designations his biographers use to describe him: historian, poet, litterrature, jurisconsult, theologian, moralist, logician, political thinker, psychologist, metaphysician, exegete, and polemicist. So-wide-ranging was his intellectual activity that he managed to devote scholarly attention to all the branches of Greek and Islamic learning, with exception of Mathematics. ${ }^{3}$

Dalam telaahnya tentang sejarah studi perbandingan agama di dunia Barat, Eric J. Sharpe, penulis Comparative Religion: A History, memberikan tempat tersendiri untuk menyebut kebesaran Syahrastânî, tokoh Muslim asal Persia ini: The honor of writing the first history of religion in world literature seems in fact to belong to the Muslim Syahrastânî, whose Religious Parties and Schools of Philosophy describes and systematizes all religion of the then known world, as far as the boundaries of China. ${ }^{4}$

\section{Motif Sarjana Muslim dalam Studi Agama dan Sekte}

Upaya sarjana Muslim Abad Pertengahan untuk menulis risalah tentang agama dan sekte-sekte agama nampaknya dilatarbelakangi oleh berbagai faktor; yang paling essensial di antaranya adalah faktor-faktor ideologis, politis, dan intelektual. Secara ideologis, terdapat sekian banyak ayat-ayat al-Qur'ân yang menyoroti

\footnotetext{
${ }^{2}$ A. Jeffery, "Al-Bîrûnî’s Contribution to Comparative Religion," dalam Al-Bîrûnî: Commemoration Volume (Calcutta: Iran Society, 1951), 125 .

${ }^{3}$ Theodore Pulcini, Exegesis as Polemical Discourse: Ibn Hazm on Jewisy and Christian Scriptures (Atlanta, Georgia: Scholars Press, 1998), 1.

${ }^{4}$ Eric J. Syarpe, Comparative Religion: A History, 2nd edition (Illinois, La Salle: Open Court, 1991), 11.
}

eksistensi komunitas agama-agama di luar Islam, seperti Shâbiâns (al-shâbiûn), Zoroastrians (almajûsiyah), maupun mereka yang sebut sebagai "Masyarakat Kitab" (ahl al-kitâb), yang dalam kenyataannya telah menarik perhatian sarjana, teolog, dan sejarahwan Muslim generasi awal untuk mengelaborasi eksistensi, status, serta posisi agama-agama "lain" melalui perspektif Islam. $^{5}$

Sementara di sisi yang lain, ketika ekspedisi dan ekspansi politik dilakukan oleh penguasa Islam sudah sampai ke beberapa wilayah strategis di Asia Selatan, Asia Tengah, Asia Timur, Afrika Utara, serta beberapa wilayah di Eropa. ${ }^{6}$ Kebutuhan untuk mengenal agama-agama lain menjadi sesuatu yang tak terhindari, baik dilatarbelakangi oleh tujuan yang bersifat politik, maupun untuk tujuan yang bersifat ideologis. Seiring dengan sifat dasar motivasi politik, dan di bawah perlindungan kekuasaan kekaisaran atau kesultanan tertentu, beberapa sarjana Muslim melakukan "studi kawasan" (regional studies) dan observasi-observasi lapangan tentang agama dan komunitas agama di daerah tersebut.

Selain itu, setelah terjadinya interaksi antara peradaban Muslim dan Yunani, ${ }^{7}$ komunikasi antarkomunitas agama dan studi tentang agamaagama telah menjadi satu konsen akademis dan ideologis tersendiri bagi sebagian sarjana Muslim abad pertengahan. Penerjemahan bukubuku berbahasa Yunani dalam bidang filsafat (philosophy) dan logika (logic) ke dalam Bahasa Arab maupun Persia pada masa kekuasaan 'Abbasiyah, misalnya, telah menjadi peristiwa penting yang memberikan kontribusi besar

\footnotetext{
${ }^{5}$ Lebih jauh lihat Jaques Waardenburg, Muslim Perception of Other Religions: A Historical Survey (New York: Oxford University Press, 1999).

${ }^{6} \mathrm{Buku}$ yang mengulas persebaran Islam di beberapa wilayah tersebut antara lain T.W. Arnold, The Preaching of Islam: A History of the Propagation of the Muslim Faith (Lahore: Kasymiri Bazar, 1961).

${ }^{7}$ Montgomery Watt, Islamic Theology and Philosophy (Edinburg: Edinburg University Press, 1987); Marsyall G. S. Hodgson, The Venture of Islam, Volume 1; The Classical Age of Islam (Chicago \& London: The University of Chicago Press, 1974), 437.
} 
bagi perkembangan filsafat dan teologi dalam khasanah tradisi intelektual Muslim. Fenomena penerjemahan ini juga secara signifikan ikut melambungkan karya-karya Muslim di bidang tasawuf (Islamic mysticism), studi budaya, maupun studi agama-agama. Periode yang disebut sebagai "the Wave of Hellenism" di dalam dunia Islam ini ditandai pula dengan kemunculan penulis-penulis Muslim prolifik yang "dipengaruhi" oleh pemikiran Yunani, budaya Arab dan tradisi intelektual Persia. ${ }^{8}$

Tentu tidak sedikit penulis, ahli geografi, astronomi, pedagang, serta pengembara Muslim yang meninggalkan catatan-catatan berharga mereka, yang di dalamnya terdapat banyak informasi tentang budaya dan agama-agama di luar Islam jauh sebelum al-Bîrûnî, Ibn Hazm, dan al-Syahrastânî menulis karya-karya mereka di bidang studi agama-agama. Lingkup kajiannya tidak terbatas kepada elaborasi tentang Yahudi atau Kristen di mana generasi Muslim awal sangat terkonsentrasi pada topik-topik tersebut. Namun, sudah mulai mendeskripsikan agama-agama India dan China, seperti yang saat ini dikenal dengan nama Agama Hindu (Hinduism) maupun Buddha (Buddhism).

Karakteristik karya-karya Muslim awal pada Abad Pertengahan (medieval Muslim literature) dalam mendeskripsikan dan mempersepsikan agama-agama di luar Islam setidaknya dapat dibagi ke dalam tiga tipe: Pertama, catatan yang bersifat geografis dan ensiklopedis, yang sebagian di antaranya ditulis berdasarkan pengalaman pribadi sang penulis (eye-witness account); kedua, risalah yang bersifat polemis-teologis; dan ketiga, karya yang bersifat heresiografis dan studi agama-agama secara khusus.

${ }^{8}$ Bayt al-Hikmah (Rumah Kebijaksanaan, House of Wisdom) di Baghdad merupakan satu fakta penting tentang bagaimana sebuah perpustakaan riset telah eksis pada masa 'Abbâsiah di mana pemikiran Yunani (Greek thought), kultur Arab (Arab culture), dan tradisi intelektual Persia (Persian intellectual environment) saling mempengaruhi. Lihat Seyyed Hossein Nashr, The Islamic Intellectual Tradition in Persia, diedit oleh: Mehdi Amin Razavi (Surrey [England]: Curzon Press, 1996), khususnya bab I, "Islamic Thought and Persian Culture," 3-58.

\section{Geneologi Pemikiran}

Sebuah adagium dan peribahasa yang sering dinisbatkan kepada Nabi Muhammad, "Carilah ilmu kendati sampai ke negeri China (uthlub al'ilm wa law bi al-sîn), menjadi indikasi bahwa peradaban Islam-Arab sudah memiliki kontak atau setidaknya informasi tentang negeri-negeri besar lainnya. Tarif Khalidi, misalnya, menuliskan bahwa sejak abad ke-8 dan 10, para sejarahwan, ahli geografi maupun petualang Muslim telah memberikan perhatian kepada tujuh peradaban besar dunia saat itu (seven great ancient nations), yaitu: Peradaban Persia, Kaldea, Yunani, Mesir, Turki, India, and China. ${ }^{9}$ Tak pelak, para sarjana Muslim periode ini menjadi begitu familiar dengan pandangan dunia (worldviews) yang berkembang di luar Jazirah Arab-Islam.

Observasi Muslim terhadap wilayah India dan China dapat dijadikan sebagai contoh. Sebagai hasil dari interaksi intensif antara Peradaban Islam dan al-Hind (India) pada Abad Pertengahan, beberapa penulis Muslim telah mengungkap pelbagai aspek peradaban al-Hind dalam risalahrisalah mereka. Menurut laporan al-Balâdzurî, bahwasanya Uthman b. 'Affan, khalifah Islam ketiga, telah memerintahkan 'Abdullâh b. 'Amr b. Kurayz untuk mengutus seseorang yang berpengetahuan cukup ke daerah perbatasan India dan mencari informasi tentang negeri tersebut. Laporan lainnya menyatakan bahwa gagasan untuk melakukan ekspedisi ke daerah al-Hind di kalangan Muslim sudah ada sejak masa Khalifah Kedua 'Umar b. al-Khaththâb. ${ }^{10}$

Secara geografis, terminologi Arab untuk India adalah al-Hind. Ketika beberapa penulis Muslim menggunakan istilah tersebut, boleh jadi berarti "India" dalam proporsi dan konsepsi orang-orang Arab-Persia. André Wink menjelaskan bahwa

\footnotetext{
${ }^{9}$ Tarif Khalidi, Classical Arab Islam: The Culture and Heritage of the Golden Age (New Jersey, Princeton: Darwin Press, 1985), 62.

${ }^{10}$ Abû al-Futûh Muhamamad al-Tawânisî. Abû Ray $\underline{h} a ̂ n$ Muhammad b. Ahmad al-Bîrûnî: al-'Ālim al-Falakî, al-Jiyâlûjî̀,wa alRiyâdhi al-Mu'arrikh Mutarajim Tsaqâfah al-Hind (Muassasah Dâr al-Tahrîr li Thab'i wa al-Nashr, 1968), 15.
} 
kata "al-Hind" sendiri berasal dari istilah yang digunakan orang-orang Persia (a pre-existing Persian term), bukan berasal dari bahasa Sanskrit. ${ }^{11}$ Pada masa Bani Umayyah dan 'Abbâsiah, istilah Arab "al-Hind" telah digunakan untuk merujuk kepada beberapa wilayah di Asia Selatan. ${ }^{12}$ Istilah geografis lain yang digunakan pada masa-masa tersebut dalam mengidentifikasi wilayah India adalah al-Sind. Al-Mas'ûdi (w. 957) dalam karyanya Murûj al-Dzahab wa Ma'âdin al-Jauhar menjelaskan, "Negeri India terbentang mulai dari perbukitan di Kurâsan dan al-Sind sampai ke daerah Tibet". ${ }^{13}$ Sejarahwan Maqbul Ahmad mencatat bahwa bila istilah al-Hind mencakup beberapa wilayah mulai dari Indus sampai perbatasan Burma, maka istilah al-Sind mencakup beberapa wilayah mulai dari Makran sampai daerah dataran rendah Indus. ${ }^{14}$ Setelah itu, orangorang Arab memodifikasi cakupan geografis dari istilah ini dengan memasukkan Kepulauan Laut Tengah (the Central Ocean Archipelagos), berikut dataran utama (mainland) dan kepulauan (island) di Asia Tenggara yang memang secara kultural telah "ter-india-kan" (culturally indianized) sejak abad ke-7. Sementara di sisi yang lain, beberapa wilayah yang dihuni mayoritas penganut Buddha ("Buddhist areas") seperti Asia Tengah, Cina,

\footnotetext{
${ }^{11}$ Andre Wink, Al-Hind: The Making of the Indo-Islamic World: Volume I: Early Medieval India and the Expansion of Islam 7-11 Centuries (Leiden, New York, Köln: Brill, 1997), 190

${ }^{12}$ Lihat Mubârakpâri, K.A. al-'Arab wa al-Hind, 13; dalam karyanya yang lain, al-Mubârakpâri secara singkat menggambarkan kebijakan politik, budaya, dan intelektual terhadap yang dikeluarkan oleh Bani 'Abbasiyah terhadap alHind baik sejak masih dipimpin oleh Abû al-Abbas al-Saffâh (750-754) sampai al-Mu'tadid (892-902). Lihat al-Hind fì 'Ahd al- 'Abbâsiyyîn (al-Qâhirah: Dâr al-Anshar, 1980)

${ }^{13}$ al-Mas'ûdî, Murûj al-Dzahab wa Ma'âdin al-Jauhar (Beirut: Makshûrât al-Jâmi'ah al-Libâniyah, 1966), I, 91; lihat juga Meadows of Gold and Mines of Gems, diterjemahkan oleh Aloys Springer (London: Printed oleh the Oriental Translation Fund of Great Britain and Ireland, 1841), I, 177.

${ }^{14}$ Untuk diskusi lebih jauh tentang catatan geografis Muslim generasi awal tentang India, lihat Maqbul Ahmad, Indo-Arab Relations: An Account of India's Relations with the Arab World from Ancient up to Modern Times (New Delhi: Indian Council for Cultural Relations; Bombay: Popular Prakashan, 1969), 95-106; juga M.A. Saleem Khan, Early Muslim Perception of India and Hinduism (New Delhi: South Asian Publishers, 1997), khususnya bab II, “Travelers and Geographers”, 156-230.
}

Jepang, dan Korea dimasukkan ke dalam istilah al-Sîn (China), sedangkan Tibet dan Mongol pada dasarnya sering diklasifikasikan sebagai bagian dari al-Hind. ${ }^{15}$

Kendati interaksi antara orang-orang Arab dan India boleh jadi memiliki akarnya sebelum peradaban Islam muncul, khususnya melalui model interaksi yang bersifat komersial (al'alâqât al-tijâriyah), ${ }^{16}$ pengetahuan Muslim tentang budaya dan peradaban India berkembang pesat sejak abad kesembilan dan kesepuluh Masehi melalui ekspedisi politik di Asia Selatan, dan melalui pengaruh penting yang mereka miliki dalam menghubungkan dua unit ekonomi di wilayah Mediterania dan Lautan India. Pengenalan Muslim terhadap budaya India tidak hanya disebabkan oleh adanya hubungan dagang antara orang-orang Arab dan India, tetapi fenomena ini berkembang justru setelah Muslim Arab menaklukkan beberapa wilayah Persia di mana orang-orang Persia sudah bercampur baur (imtizâj) dan familiar dengan kultur India (al-thaqâfât al-hindiyyah). ${ }^{17}$ Interaksi antarperadaban tersebut menjadi satu fondasi yang memungkinkan para sarjana dan penulis Muslim untuk memberikan perhatian lebih jauh terhadap kebudayaan India, yang antara lain mencakup sistem kepercayaan maupun komunitas agamanya. Fenomena ini juga semakin memperluas wawasan dan pengetahuan sarjana Muslim terhadap agama-agama lain yang eksis, tidak hanya di wilayah Arab dan Persia, tetapi

\footnotetext{
${ }^{15}$ Wink, Al-Hind, Volume I, 191-92; Karl Jahn, Rashîd al-Dîn's History of India: Collected Essays with Facsimiles and Indice (London \& Paris: The Hague, Mouton \& CO., 1965) Rashîd al-Dîn dalam karyanya Jâmi' a-Tavârikh lebih focus kepada "Buddhisme" daripada "Hinduisme."

${ }^{16}$ Mubârakpâri, K.A., al-'Arab wa al-Hind fì 'ahd alRisâlah [diterjemahkan oleh Abd al-Aziz 'Izzat 'Abd alJalil] (al-Qahirah: al-Haiah al-Mishriyyah al-'Ammah li al-Kitâb, 1973), 10.

${ }^{17}$ Abû al-Futûh Muhammad al-Tawânisî, Abû Rayhân Muhammad b. Ahmad al-Bîrûnî: al-'Ālim al-Falakî, alJiyâlûjî, wa al-Riyâdhi al-Mu'arrikh Mutarajim Thaqâfah al-Hind (Muassasah Dâr al-Tahrîr li Thab'i wa al-Nashr, 1968), 19-20; Wink, Al-Hind: Volume I, 7-9.
} 
juga di negeri India ${ }^{18}$ dan China. ${ }^{19}$

Sejarahwan besar Muslim di Abad Pertengahan, Muhammad b. Jarir al-Thabarî (w. 923) dalam Tarîkh al-Rusul wa al-Mulûk (Sejarah Para Nabi dan Raja), misalnya, telah memasukkan materi tentang al-Hind dan tradisi keagamaan mereka serta keterkaitannya dengan "manusia pertama" di muka bumi ini. Thabarî mendeskripsikan beberapa riwayat yang mengindikasikan bahwa Adam diturunkan dari Surga ke bumi, di tanah al-Hind, khususnya di suatu bukit yang disebut Budh. Adam kemudian meninggalkan India setelah diperintahkan Tuhan untuk melakukan ibadah haji ke Tanah Suci Makkah. ${ }^{20}$ Menurut riwayat-riwayat yang dipakai oleh Thabarî, "pemujaan terhadap berhala" (idolatry) dimulai ketika keturunan Adam, yakni anak keturunan Syeth dan Cain, memuja tubuh para leluhurnya. Pada masa Nuh, banjir bandang kemudian membawa objek-objek atau patung-patung pujaan tersebut ke wilayah Arabia.

Dengan mengutip anekdot dan riwayat yang terdapat di dalam kitab al-Thabarî tersebut, penulis bermaksud menjelaskan bahwa narasinarasi tentang India sudah ada dalam literatur Muslim awal. Bahkan, narasi-narasi tersebut juga menunjukkan bahwa hubungan antara tanah Arab dan India sudah terjadi sejak "masa primordial," yakni ketika Adam pergi ke "Rumah Tuhan" untuk melakukan Haji sekaligus mencari Hawa, yang menurut narasi-narasi dalam Kitab

\footnotetext{
${ }^{18}$ Bahkan jauh sebelum "Gelombang Helenisme" memasuki ranah budaya Arab-Persia Islam pada abad kedelapan dan kesepuluh, para sarjana Muslim Arab-Persia telah dapat mengakses sumber-sumber dan materi-materi pengetahuan India dalam bidang astronomi, astrologi, matematika, dan kedokteran yang diterjemahkan dari Bahasa Sanskrit ke dalam bahasa Arab atau Persia. Lihat Dimitri Gutas, Greek Thought, Arabic Culture: The Graeco-Arabic Translation Movement in Baghdad and Early 'Abbâsid Society [2 $2^{\text {nd }}-4^{\text {th }} / 8^{\text {th }}-10^{\text {th }}$ centuries] (London: Routledge, 1998), 24.

${ }^{19}$ Sulaymân al-Tâjir and Abî Zayd Hasan al-Sirâfî, Akhbâr al-Sîn wa al-Hind, tahqîq Yûsuf al-Syârûnî (al-Qâhirah: al-Dâr al-Mishriyyah al-Banâniyah, 1999).

${ }^{20}$ Abû Ja'far Muhammad b. Jarîr al-Thabarî. The History of al-Thabarî (Ta'rîkh al-Rusul wa al-Mulukk [diterjemahkan and dianotasi oleh Franz Rosenthal], Volume I (Albany: State University of New York Press, 1989), 291-292, 308.
}

al-Thabarî diturunkan di Muzdalifah. Anekdot tersebut juga mengisyaratkan bahwa pemujaan berhala, berdasarkan penjelasan Thabarî, juga berasal dari India. ${ }^{21}$

Di luar karya Thabarîyang banyak mengadopsi informasi anekdotal dan sulit untuk diverifikasi, beberapa eksposisi telah ditulis oleh petualang Muslim (Muslim travelers) dan ahli geografi, yang secara partial menyediakan informasi tentang tradisi agama-agama India. Ahli geografi Abû al-Qâsim b. 'Ubaydillâh 'Abdullâh b. Khurdâdzbih (w. 912) secara singkat melaporkan karakteristik kasta India (ajnâs al-hind) dan empat puluh dua aliran kegamaan India (milal ahl al-hind). Tanpa menyajikan elaborasi yang cukup mendalam, dalam karyanya al-Masâlik wa al-Mamâlik (Risalah tentang Jalur-jalur dan Raja-raja) Khurdâdzbih membedakan aliranaliran agama tersebut ke dalam tiga kelompok utama: (1) mereka yang beriman kepada Sang Pencipta Yang Mahabesar dan Mahakuasa (man yuthbitu al-khâliq azza wa jalla); (2) mereka yang menolak atau tidak percaya dengan [konsep] keNabi-an (man yanfâ al-rusul); dan mereka yang tidak beriman kepada Yang Mahakuasa dan tidak percaya dengan konsep kenabian (wa minhum al-nâfî li kulli dzâlik).22

S. Maqbul Ahmad dalam komentarnya terhadap karya Khurdâdzbih tersebut menjelaskan bahwa persepsi Khurdâdzbih tentang aliran-aliran agama dan tradisi keagamaan India ini kemungkinan besar merujuk kepada karya Gardizî, Akhbâr al-Sîn wa al-Hind (Pembahasan tentang China dan India). Gardizî mengklasifikasikan falsafah dan tradisi agama India kepada sembilanpuluhsembilan bagian yang dapat diringkaskan menjadi empatpuluh-dua aliran utama. Berdasarkan

\footnotetext{
${ }^{21}$ Lihat Yohanan Freidmann, "Medieval Muslim views of Indian Religions," Journal of the American Oriental Society 95 (1975), 214.

${ }^{22}$ Lihat Abû al-Qasim b. 'Ubaydillah 'Abdullâh b. Khurdâdzbih, Al-Masâlik wa al-Mamâlik (Damascus: Manshûrât wa Zârat al-Thaqâfah, 1999), 105. Lihat juga S. Maqbul Ahmad, Arabic Classical Accounts of India and China, Book I (Calcutta: Indian Institute of Advance Studies1989), 7.
} 
karya Gardizî tersebut, boleh jadi bahwa yang dimaksud oleh Khurdâdzbih dengan kelompok pertama adalah Brahmans, kelompok kedua adalah Srâmanas, dan kelompok ketiga dapat dihubungkan dengan Hinayana Buddhists. ${ }^{23}$

Karya lain tentang al-Hind yang memiliki judul serupa dengan karya Gardizî di atas adalah risalah yang ditulis pelancong Muslim Sulaymân al-Tâjir (w.?), berjudul Akhbâr al-Sîn wa al-Hind. Ia membuat satu perbandingan antara geografi, budaya, dan masyarakat India dan China. Sayangnya, perhatian al-Tâjir terhadap agamaagama India tidaklah seserius dan se-elaboratif karyanya Gardizî. ${ }^{24}$ Al-Tâjir menggarisbawahi hubungan kultural antara India dan China dan menekankan bahwa tradisi agama-agama China, khususnya Buddhisme, berakar dari India (wa innamâ ashlu diyânatihim min al-hind). Kemudian, menurutnya, orang-orang India membawa patung-patung pujaan mereka ke China. Ia juga mencatat bahwa baik orang-orang China (ahl al-sîn) maupun orang-orang India (ahlal-hind) memiliki sistem kepercayaan hampir sama, yakni mereka sama-sama berkeyakinan bahwa mereka "dapat berkomunikasi dengan berhala-berhala sesembahannya" (yaz'amûna anna al-bidâdah takallamahum). Al-Tâjir selanjutnya memberikan perhatian terhadap dimensi mistik dan spiritual agama-agama India dan China. Menurutnya, kendati masing-masing tradisi memiliki bentuk praktik keagamaan yang berbeda, orang-orang India dan China percaya dengan konsep inkarnasi, perpindahan jiwa ("metempsychosis" atau "transmigration of souls") atau yang disebut dengan tanâsukh. ${ }^{25}$

\footnotetext{
${ }^{23}$ Maqbul Ahmad, Arabic Classical Accounts, 9.

${ }^{24}$ Karena Sulaymân al-Tâjir and Hasan al-Sirâfî menggunakan judul yang sama untuk karya mereka, versi yang saya gunakan dalam tulisan ini diedit oleh Yûsuf al-Syârûnî. Buku ini dibagi kepada dua bagian: bagian pertama merupakan karya Sulaymân al-Tâjir, sementara bagian berikutnya milik Abî Zayd Hasan alSirâfî, Akhbâr al-Sin wa al-Hind, tahqiq Yûsuf al-Syârûnî (alQâhirah: al-Dâr al-Mishriyyah al-Banâniyah, 1999).

${ }^{25}$ Al-Tâjir, Akhbâr al-Sîn wa al-Hind, 56; Maqbul Ahmad, Arabic Classical Accounts, 55-56 dan 79; juga lihat al-Mas'ûdi, Murûj al-Dzahab, 91.
}

\section{Risalah yang bersifat Polemis-Teologis}

Di samping karya-karya deskrisptifensiklopedis yang lebih bernuansa "sosiologisantropologis," beberapa sarjana Muslim, khususnya teolog dan heresiograf telah menaruh minat yang lebih terhadap persoalan dan tematema yang bersifat teologis-polemis. Pendekatan seperti ini sangat kentara di dalam literatur Muslim dalam bidang studi agama, bukan saja pada abad pertengahan, melainkan di era modern sekalipun. Ketegangan politik antara kaum Muslim dan umat beragama lain, khususnya kaum Yahudi dan Kristen, sejak masa awal Islam sampai beberapa periode kekhalifahan, terutama di masa Ummayyah dan 'Abbâsiyah, telah menjadi dasar bagi sarjana dan teolog Muslim untuk mengkaji agama Yahudi dan Kristen secara lebih serius. Perlu ditambahkan di sini bahwa polemik yang bersifat teologis di kalangan teolog Muslim generasi abad pertengahan bukan saja ditujukan kepada penganut agama-agama di luar Islam, namun, seiring dengan perkembangan corak teologi yang semakin beragam di dunia Muslim, polemik-polemik teologis tersebut terjadi juga di kalangan Muslim sendiri. Hal ini ditandai dengan berbagai karya yang muncul yang merepresentasikan perkembangan heresiografi dalam literatur Muslim awal.

Pada bagian ini penulis akan menggambarkan secara singkat corak risalah teolog Muslim yang bersifat polemis-apologetis. Salah satu tema yang senantiasa dijadikan argumen utama dan sekaligus menjadi landasan kritik sarjana Muslim terhadap tradisi biblikal, agama Yahudi dan Kristen, adalah konsep tahrif. Dalam mendikusikan tradisi biblikal maupun konsep heresi dalam Islam, mayoritas sarjana dan teolog Muslim memiliki pendekatan, teknik analisis, dan metode yang hampir sama, yakni polemis dan apologetis sekaligus. Namun demikian, sesuai dengan corak keilmuan dari generasi ke generasi yang semakin berkembang, sifat polemis dan apolegetis itu bukan berarti tidak menunjukkan sofistikasi dan ketajaman tulisan 
dari para pengarangnya. Terlihat bahwa antara generasi abad ke-9 dan 10, nomenklatur dan perspektif yang digunakan menunjukkan beberapa perbedaan. Meskipun demikian, pembahasan mereka pada umumnya berakhir pada muara yang sama, yaitu menunjukkan superioritas Islam terhadap agama-agama lainnya.

Marilah konsep tahrif kita lihat sebagai contoh kasus. Di dalam al-Qur'ân terdapat beberapa keterangan yang menyinggung masalah tahrif. Secara etimologis, istilah tahrif berarti, korupsi, falsifikasi, modifikasi, menyimpangkan, misinterpretasi, dan salah paham. Istilah ini sering digunakan para teolog Muslim untuk "mengkritik" penganut Yahudi dan Kristen bahwa mereka sudah "salah paham" dan "salah interpretasi" terhadap isi kandungan kitab suci mereka. Sebagian lain berpendapat bahwa kaum Yahudi dan Kristen telah "mengubah" (baddala) keaslian kitab suci mereka, terutama dengan "menghilangkan" informasi tentang kabar kedatangan dan sifat-sifat Muhammad sebagai Nabi terakhir.

Gagasan seperti di atas bukan tanpa dasar teologis. Dalam al-Qur'ân disebutkan bahwa Kaum Yahudi telah "mengubah" kitab suci (yuharrifûna) informasi atau ayat-ayat yang telah mereka terima dari Allâh SWT. ${ }^{26}$ Mengenai kitab suci Yahudi, al-Qur'ân menyebutkan pula bahwa ada sebagian dari mereka yang menulis kitab dengan tangan mereka dan kemudian mereka mengaku-aku bahwa, "[kitab] ini berasal dari Tuhan" (hâdzâ min 'ind-i-1lâh). ${ }^{27}$ Pernyataan senada juga terdapat dalam ayat lainnya yang menyatakan bahwa kaum Yahudi telah mengubah perkataan dari tempat-tempatnya (yuharrifûna alkalima 'an mawâdhi' ihi). ${ }^{28}$ Dengan menggunakan istilah yang lain, al-Qur'ân menyebutkan bahwa umat Kristiani telah "dengan sengaja melupakan" (fanasû) sebagian dari apa yang telah diberikan

\footnotetext{
${ }^{26}$ QS. al-Baqarah [2]: 75.

${ }^{27}$ QS. al-Baqarah [2]: 79.

${ }^{28}$ QS. al-Nisâ' [4]: 46.
}

Allâh kepada mereka sebagai peringatan. ${ }^{29}$ Selain itu, al-Qur'ân menggunakan istilah "distorsi" dan "memutarbalik lidah" (yalûna alsinatahum ${ }^{30}$ atau layyan bialsinatihim). ${ }^{31}$ Pada keterangan lain disebutkan bahwa Kaum Yahudi dan Kristen atau yang disebut dengan Masyarakat Kitab (ahl al-kitâb) telah "menyembunyikan kebenaran" (layaktumûna al-haqq). ${ }^{32}$

Beraneka ragamnya terminologi yang digunakan dalam al-Qur' ân untuk mengidentifikasi eksistensi kaum Yahudi dan Kristen, seperti istilah "mengubah kitab," "mengubah perkataan," "distrosi atau memutarbalik lidah," "sengaja melupakan," dan "menyembunyikan kebenaran," berakhir pada konsekuensi bahwa para sarjana dan teolog Muslim memiliki pendapat yang berbeda-beda dalam menilai non-Musim, khususnya Yahudi dan Kristen. Tentu saja, perbedaan persepsi Muslim terhadap Yahudi dan Kristen merupakan buah dari perbedaan interpretasi mereka terhadap teks-teks al-Qur'ân. Lebih dari itu, fakta teologis ini, selain fakta-fakta sosiologis dan politis hubungan antara Muslim dan non-Muslim pada abad pertengahan, menjadi satu situasi tersendiri bagi para teolog Muslim untuk mengelaborasi lebih jauh agama-agama sebelumnya, khususnya mengenai "otentisitas" kitab suci mereka.

Observasi Camila Adang ${ }^{33}$ dan Theodore Pulcini $^{34}$ terhadap karya-karya Muslim abad pertengahan menunjukkan bahwa terdapat nuansa atau perbedaan aksentuasi dari teolog Muslim dalam menilai "tradisi biblikal". Theodore Pulcini, misalnya membagi dua periode penting

\footnotetext{
${ }^{29}$ QS. al-Mâidah [5]: 14.

${ }^{30}$ QS. Āli-'Imrân [3]: 78

${ }^{31}$ QS. al-Nisa' [4]: 46.

${ }^{32}$ QS. al-Baqarah [2]: 146; Āli-'Imrân [3]: 71.

${ }^{33}$ Tentang perbedaan pandang Muslim terhadap konsep tahrîf dan persepsi mereka mengenai agama Kitab agama Yahudi, lihat Camilla Adang, Muslim Writers on Judaism and The Hebrew Bible: From Ibn Rabban to Ibn Hazm (Leiden, New York, and Koln: E.J. Brill, 1996), khususnya bab V, "The Proofs of Prophethood," 139-191.

${ }^{34}$ Theodore Pulcini, Exegesis as Polemical Discourse, khsusnya bab II "The Treatise on Contradiction and Lies in Its SocioCultural Context," 13-39.
} 
berkembangnya karya-karya sarjana dan teolog Muslim yang mengulas konsep tahrif tersebut, yakni karya-karya yang ditulis antara abad ke- 8 dan 9, serta karya-karya yang muncul pada abad kesepuluh dan kesebelas Masehi. Al-Qâsim b. Ibrâhim (w. 860) dan Abû 'Utsmân 'Amr b. Bahr al-Fuqaymî al-Basyri atau dikenal dengan al-Jâhiz (w. 869) yang menulis buku dengan judul sama, Radd 'alâ al-Nashâra (Bantahan terhadap Penganut Agama Kristen) merupakan salah satu contoh generasi awal "Kristolog" Muslim yang mencoba menafsir Bibel dan mencari celah untuk menunjukkan superioritas Islam. Begitu pula dengan Kitâb al-Dîn waal-Daulah (Risalah tentang Agama dan Pemerintahan)-nya 'Ali b. Rabban al-Thabarî atau dikenal dengan Ibnu Rabban (w. 825[?]) maupun Dalâil alNubuwwah (Bukti-bukti Kenabian) milik Abû Muhammad 'Abd Allâh b. Qutayba (w. 889). Karya-karya yang ditulis abad ke-9 dan 12 memang pada umumnya memaknai tahrif sebagai "textual misinterpretation" ketimbang "textual corruption." Kendati sarjana Muslim abad ke-8 dan ke-9 konsen dengan "textual corruption," namun elaborasinya terhadap konsep tahrif tidak mendalam.

Hal ini berbeda dengan generasi berikutnya, abad ke-10 dan generasi seterusnya, di mana al-Thabarî dan sarjana yang segenerasi dengannya memunculkan argumen secara lebih "sophisticated," meskipun tetap dalam kerangka polemis-apologetis. Jarîr al-Thabarî, misalnya, meskipun disinyalir sering menggunakan riwayat isrâiliyyat, memiliki konsepsi dan persepsi tersendiri tentang tahrif. Dengan karakter tulisannya yang senantiasa menggunakan isnad (chain of transmission), al-Thabarî menilai bahwa "orang-orang Yahudi menulis Kitab Suci mereka berdasarkan interpretasi mereka sendiri, yang itu bertentangan dengan apa yang telah Tuhan turunkan kepada para nabinya."'elain itu, ia melakukan "kritik sanad" terhadap proses penulisan ulang Kitab Suci Yahudi (Jewish Scripture) dengan menilai bahwa Taurat sudah terbakar ketika orang-orang Yahudi tertahan oleh Nebukadnezar saat orang-orang Israel akan kembali ke Palestina.

Sementara itu, al-Mas'ûdî dalam Murûj al-Dzahab wa Ma'âdin al-Jawhar (Hamparan Emas dan Tambang Perhiasan), mengindikasikan bahwa tahrif terjadi dalam konteks "interpretasi." Sedangkan al-Maqdisî atau Abu Nashr Muthahhar Ibn Thâhir dalam Kitâb al-Bad' wa al-Tarîkh (Risalah tentang Penciptaan dan Sejarah), memahami tahrif dalam konteks "tahrif al-nass" dan “tahrif al-ma'âni”" sekaligus. Beberapa sarjana dan teolog Muslim lainnya yang memasukkan tema-tema yang bersifat perdebatan teologis ke dalam tulisan mereka antara lain, Abû Tûsuf Ya'qûb b. Inshâq al-Qirqisânî yang menulis Kitâb al-Anwar wa al-Marâghib (Risalah tentang Cahaya-cahaya dan Menara Pengawas), termasuk

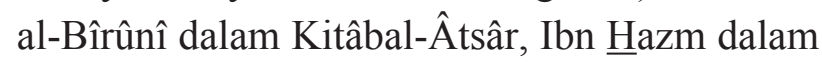
Kitâbal-Fishal, serta al-Syahrastâni dalam Kitâbal-Milal.

Terhadap kecenderungan "teknik pengopinian" (trends in tones) yang berkembang dalam literatur Muslim sebagai respons mereka terhadap agama Yahudi dan Kristen, Pulcini menyimpulkan bahwa selain bersikap kritis, para penulis Muslim juga menunjukkan pengendalian yang luar biasa ketika mengevaluasi orang-orang Yahudi dan Kristen; sikap mereka terhadap kitabkitab suci sebelumnya sering terlihat ambivalen, ditandai dengan "keengganan untuk menolak mentah-mentah" (reluctance to condemn them unreservedly). Bahkan dalam konteks tertentu, kritik Muslim terhadap agama lain lebih ditandai dengan bentuk toleransi (toleration) ${ }^{35}$ ketimbang polemis. ${ }^{36}$

Di samping reaksi terhadap Yahudi dan Kristen yang memang merupakan agama "serumpun" dengan Islam, agama-agama non-

\footnotetext{
${ }^{35}$ Toleransi dapat diartikan sebagai sikap pengakuan resmi (official acceptance) oleh sebuah pemerintahan (dalam kasus ini bisa jadi seseorang) terhadap suatu kepercayaan dan praktik keagamaan yang berbeda dari ajaran [resmi] yang dipeluknya. ${ }^{36}$ Pulcini, Exegesis as Polemical Discourse, 42-43.
} 
biblikal juga tak luput dari telaah sarjana dan teolog Muslim. Bila pada periode Islam awal, 610-650 Masehi, lingkup respons Muslim terhadap agama-agama lain masih terbatas pada Masyarakat Kitab (ahl al-kitâb), yaitu Kristen dan Yahudi, dan penganut Paganisme Arab PraIslam, maka pada Abad Pertengahan, 650-1500 Masehi, lingkup kajian literatur Muslim tentang agama-agama lain sudah lebih luas, antara lain dengan munculnya karya-karya khusus tentang agama Hindu dan Buddha, Majusi/Mazdaisme/ Zoroaster, dan Manikean. Bila dua agama pertama tersebar luas di daratan Asia Selatan dan Timur, maka dua agama terakhir eksis utamanya di daratan Transoxania (Iran). Irânshahrî (hidup sekitar akhir abad ke-9), Ibn Nadzim (w. 987), dan Rashîd al-Din (w. 1318) adalah nama-nama sarjana Muslim yang memberi perhatian cukup besar terhadap agama Buddha dalam kajiankajian mereka. Sementara al-Bîrûnî, Ibn Hazm, dan al-Syahrastânî, kendati sempat mengulas Buddha, namun pembahasan mereka lebih banyak kepada agama-agama India (Hinduisme). Al-Bîrûnî dalam al-Âtsâr, al-Syahrastânî dalam Kitâb al-Milal, al-Khawârizm dalam Mafâtih al'Ulûm juga secara parsial mendiskusikan Majusi dan Manikean.

\section{Karya yang bersifat Heresiografis}

Heresiografi adalah ilmu tentang sektesekte atau aliran-aliran. Dalam Encyclopedia of Religion disebutkan bahwa terminologi "heresi," akar dari heresiografi, berasal dari bahasa Yunani "hairesis," yang dapat berarti "perampasan" atau "perebutan" (seizure), "pilihan" (choice, election), dan "keputusan atau upaya yang menentukan" (decision or purposive effort). Makna yang terakhir disebut menjadi titik pijak tradisi Yunani maupun Kristen dalam memaknai istilah "heresi" dengan "doktrin," "aliran," dan "gagasan atau opini yang diterima (received opinion)." Pada mulanya, term ini "bebas nilai," tidak memiliki kesan negatif. Namun demikian, situasi ini bergeser setelah Perjanjian Baru menggunakan istilah ini dalam pengertian negatif. Secara semantik, istilah "hairesis" kemudian menjadi istilah teknis untuk "heresi" yang berlaku untuk mengidentifikasi aliran Gnostik maupun sekte-sekte agama Yahudi dan tradisi Yunani. Dewasa ini, makna pejoratif "heresi" adalah "ajaran yang keliru" (erroneous teaching) atau "keyakinan yang tidak benar" (false belief). ${ }^{37}$ Dengan demikian, dalam terminologi keagamaan, hemat penulis, heresiografi adalah "ilmu yang mempelajari aliran, ajaran atau sekte yang menyimpang dari kebenaran utama."

Konsep mayoritas-minoritas dan relasi kuasailmu pengetahuan berlaku dalam konteks ini. Istilah heresi sendiri, yang dalam bahasa Indonesia bisa disebut "sempalan" atau "sektarian," senantiasa berdampingan dengan lawan katanya, ortodoksi. Di mana terdapat kelompok-kelompok agama "sempalan" atau "sektarian," maka di situ ada ortodoksi atau arus utama (mainstream). Probabilitas sebuah kekuasaan yang mengadopsi satu arus model keagamaan tertentu untuk dijadikan sebagai agama resmi (official doctrines) sangatlah besar untuk memberi cap "heretik" atau "menyimpang" terhadap model keagamaan lain yang berbeda yang diikuti oleh sekelompok kecil penganutnya. Dalam sejarah Kristen, umpamanya, paham-paham keagamaan yang tidak sesuai dengan, atau bersikap oposisi terhadap Otoritas Gereja, sering mendapat cap heretik. Demikian pula dalam khazanah tradisi agama-agama, kelompok-kelompok sempalan yang berbeda dari mainstream ini sering juga disebut heterodoksi, lawan dari ortodoksi.

Konsep ortodoksi dan heresi sesungguhnya merefleksikan perebutan klaim dan otoritas tentang "kebenaran" atau "otentisitas" sebuah tradisi. Konsep heresi umumnya menemukan tempat untuk berkembang biak dalam tradisi "agama samawi" yang memiliki formula keagamaan berdasarkan teks-teks yang diatribusikan sebagai Kitab dari Tuhan. Dengan kata lain, heresi

${ }^{37}$ Lihat ER, Vol. 6, article "Heresy,", 269-270. 
tumbuh subur dalam tradisi agama yang telah mengalami proses kanonisasi. Sebaliknya, dalam agama-agama yang belum mengalami proses kanonisasi secara rigid, "agama-agama lokal" umpamanya, konsep heresi sangat jarang diberlakukan. Dalam proses sinkretisme antara tradisi kepercayaan lokal dengan agama-agama besar, umpamanya, agama mainstream biasanya menilai "tradisi baru" hasil sinkretisme tersebut sebagai heretik .

Di dalam khazanah al-Qur'ân sendiri tidak terdapat istilah yang pas untuk diidentikan dengan konsep heresi. Dalam Encyclopedia of the Qur'ân disebutkan beberapa istilah yang memiliki kedekatan makna terhadap heresi antara lain bid'ah yang berarti "inovasi" atau "penambahan." Kata lainnya, meskipun kurang tepat untuk diasosiasikan dengan heresi, adalah 1-h-d (penghujjatan), n-f-q (hipokrit), atau b-gh-y (pembangkangan). Namun demikian, bila kita menggunakan analisis mayoritas-minoritas serta relasi kuasa dan ilmu pengetahuan, maka ketiga istilah terakhir kurang tepat untuk disepadankan dengan konsep heresi atau bid'ah. ${ }^{38}$ Ada pula istilah lain yang sering digunakan para heresiograf Muslim, yakni râfidha atau rawâfidh yang berarti "orang-orang yang menolak" dan sering diatribusikan kepada kelompok Syî'ah. Akan tetapi istilah tersebut bukan istilah yang digunakan al-Qur'ân. Menurut beberapa kalangan, istilah râfidha diperkenalkan oleh Syî'ah Zaydiyah kepada seterunya Syi'ah Ithna 'Asyariyyah yang kemudian diadopsi oleh tradisi Sunnî.

Uniknya, cara pandang "minor" terhadap entitas agama lain melalui konsep heresi ini lambat laun bergeser menjadi sebuah studi tersendiri, studi sekte-sekte atau aliran keagamaan. Bila di kalangan misonaris dan orientalis Barat pada abad ke-18 sampai awal abad ke-20, observasi mereka terhadap "agama-agama heretik" nonKristen berkembang menjadi studi agama-agama, maka di kalangan sarjana Muslim fenomena yang

\footnotetext{
${ }^{38}$ Lihat EQ, Vol. 2, article "Heresy,", 420-422.
}

sama juga terjadi, di mana telaah terhadap sektesekte non-mainstream menjadi heresiografi yang bersifat ensiklopedis. ${ }^{39}$ Mengenai perkembangan analisis heresiografis di kalangan sarjana dan teolog Kristen ke arah studi agama, Kurt Rudolph menjelaskan:

... traditional concept of heresy is no longer applicable today; it must yield its place to the historical insight that heresy and orthodoxy are relative terms for religio-historical processes of quite different kinds. In any case the history of religions has no rooms for a theological and dogmatic judgment of these processes. It uses the concepts as purely historical categories or, better, as umbrella terms that make it possible to manage, in some degree, the multiplicity of the contents presented by the history of religion. ${ }^{40}$

Dalam konteks Islam, skisme sosial-politik di kalangan Muslim generasi awal pascameninggalnya Nabi Muhammad menjadi salah satu pemicu keanekaragaman teologi Islam, dan sekaligus menjadi cikal bakal perkembangan literatur Islam. Meminjam ilustrasi Mahmoud Ayoub, “...Muslim history, properly speaking, begins not with the career of the Prophet, nor even with his migration, but with his death." ${ }^{\prime 1}$ Ayoub dalam pernyataan tersebut nampaknya ingin menekankan bahwa krisis politik yang

\footnotetext{
${ }^{39}$ Lihat umpamanya, Abû Mansûr al-Baghdâdî, al-Farq bain al-Firaq wa Bayân al-Firqah al-Nâjiyah Minhum: 'Aqâid al-Firq al-Islâmiyyah wa Ārâ Kibâr A'lâmahâ (Cairo: Maktabah Ibn Sînâ li al-Nashr wa al-Tauzî' wa alTashdîr); juga Muslim Schisms and Sects, diterjemahkan oleh: Kate Chambers Seeley (New York: AMS Press, 1966); Abû al-Muzaffar Thâhir ibn Muhammad alIsfarâynî, Tabsîr fî al-Dîn wa Tamyîz al-Firqah al-Nâjiyah 'an al-Firq al-Hâlikîn (al-Qahirah [Cairo]: Matba'ah alAnwar, 1940); 'Āli ibn Ahmad Ibn Hazm, al-Fisl fì alMilal wa Ahwâ wa al-Nihal, tahqiq Muhammad Ibrâhîm Nashr and Abûdurrahman Umayrah (Jeddah: Syairkah Maktabah Ukad, 1982).

${ }^{40}$ Lihat ER, Vol. 6, article "Heresy,", 269-270.

${ }^{41}$ Mahmoud M Ayoub, The Crisis of Muslim History: Religion and Politics in Early Islam (Oxford: Oneworld, 2003), vii. Dalam buku ini Ayoub mengulas secara cukup detail keteganganketegangan politik di kalangan para sahabat pasca meninggalnya Nabi Muhammad Saw. Karya lain yang patut dijadikan tujukan adalah Madelung, Wilfred. The Succession to Muhammad (Cambridge: Cambridge University Press, 1997)
} 
berimplikasi pada munculnya benih-benih perselisihan teologis dan bahkan peperangan di kalangan Muslim dimulai setelah Nabi Muhammad wafat. Munculnya Khawârij, yang kemudian disusul dengan perkembangan Syi'ah (pengikut dan pengagum Alî b. Abî Thâlib beserta keturunannya), dan juga menguatnya Mu'tazilah sebagai salah satu mazhab dalam Islam, plus dengan munculnya sekte-sekte Islam lainnya, telah mengukuhkan hasrat sebagian teolog dan sarjana Muslim mainstream untuk menyusun karya heresiografi mereka.

Di luar itu, narasi-narasi propetik (hadis) juga telah memberi ruang tersendiri bagi perkembangan heresiografi. Sebuah narasi tentang "perpecahan umat" yang dinisbatkan kepada Nabi Muhammad telah menjadi landasan utama para sejarahwan agama dan heresiograf Muslim awal. Tiga riwayat tentang perpecahan umat (iftirâq al-ummah) melalui "jalur" Abû Hurayrah, 'Abdullâh b. 'Umar dan Anas b. Malik acap menjadi landasan heresiograf Muslim.

Diriwayatkan oleh Abû Hurayrah, bahwasanya Rasulullâh Saw. bersabda: "Orang-orang Yahudi akan terpecah (iftaraqat) menjadi tujuh puluh-satu sekte, dan orang-orang Kristen akan terpecah menjadi tujuh puluh-dua sekte (firqah), sementara umatku akan terpecah (taftariqu) menjadi tujuh puluh-tiga sekte." ${ }^{42}$

Diriwayatkan oleh 'Abdullâh b. Umar, bahwasanya Rasulullâh Saw. bersabda: "Niscaya akan terjadi apa yang telah menimpa Banî Isrâ'îl, di mana Banî Isrâ'îl ini terpecah (tafarraqa) menjadi tujuh puluh-dua kelompok, dan akan terbagi umatku (sataftariqu) menjadi tujuh puluh-tiga kelompok (millah), termasuk ada satu kelompok lainnya. Semua kelompok-kelompok tersebut (kulluhum) akan masuk neraka, kecuali kelompok yang satu itu." ${ }^{43}$

Diriwayatkan oleh Anas b. Malik, bahwasanya

${ }^{42}$ al-Baghdâdî, al-Farq bain al-Firaq, 23; Muslim Schisms and Sects, 21.

${ }^{43}$ al-Baghdâdî, al-Farq bain al-Firaq, 24; Muslim Schisms and Sects, 21.
Rasulullâh Saw. bersabda: "Sesungguhnya Banî Isrâ'îl terpecah menjadi tujuh puluh-satu sekte (firqah), dan sesungguhnya umatku akan terpecah (sataftariqu) menjadi tujuh puluhdua sekte (firqah), seluruh kelompok tersebut (kulluhâ) masuk neraka kecuali yang satu, yakni al-Jamâ'ah." ${ }^{" 44}$

Dengan keterbatasan tempat dalam tulisan ini, penulis tidak akan masuk lebih detail untuk memberikan "kritik sanad" maupun "kritik matan" terhadap otentisitas riwayat di atas, baik mengenai perbedaan jumlah kelompok yang disebutkan dalam hadis tersebut maupun perbedaan istilah yang digunakan, seperti firqah atau millah. Yang hendak ditekankan di sini adalah bahwa riwayatriwayat tersebut nampaknya telah memberikan inspirasi bagi para teolog dan sarjana Muslim untuk menulis karya-karya heresiografi mereka, khususnya tentang sekte-sekte dalam Islam.

Selanjutnya, persepsi dan penilaian Muslim awal terhadap agama-agama non-Islam berkembang menjadi sebuah telaah khusus yang di kemudian hari melahirkan karya-karya di bidang heresiografi. Muhammad Ali AmirMoezzi, misalnya mencatat:

The development of the concept of heresy in Islam in its intellectual and literary expression can be seen in the transition from "books of refutation" (kutub al-radd), where religious doctrines are presented in contrastive format, to the progressive systematization of theological orthodoxy in the heresiographical works...... ${ }^{45}$

Beberapa karya heresiografi Islam antara lain ditulis oleh Abû al935/936) melalui karyanya Maqâlat al-Islâmiyyîn wa Ikhtilâf al-Mushallîn (Opini-opini [teologis] Muslim dan Perselisihan Orang-orang Yang Salat $)^{46}$ dan al-Ibânah 'an al-'Ushûl al-Diyânah

\footnotetext{
44al-Baghdâdî, al-Farq bain al-Firaq, 25; Muslim Schisms and Sects, 22.

${ }^{45}$ Lihat EQ, Vol. 2, article "Heresy,", 420-422.

${ }^{46}$ Abû al-Hasan 'Alî b. 'Ismâ'îl al-'Asy'arî, Maqâlat alIslâmiyyînwa Ikhtilâf al-Mushallîn, bi-tahqị̂ Muhammad Muhyî̂ al-Dîn 'Abd al-Hamîd, (al-Qâhirah, Maktabat al-Nahdhah
} 
(Uraian tentang Fondasi-fondasi Islam). ${ }^{47}$ AlAsy'arî sendiri merupakan pengikut Ahmad b. Hanbal, dan belakangan mazhab Asy'ariyah menjadi salah satu mazhab teologi terbesar di kalangan Muslim. Al-Ghazâlî merupakan salah satu filsuf dan teolog besar dari mazhab ini. Karya-karya al-Asy'arî dalam bidang heresiografi ditulis setelah dia keluar dari mazhab Mu'tazilah karena ketidakpuasannya terhadap argumen dan penjelasan teologis gurunya yang Mu'tazilah, al-Jubâ'î. Bila dalam Kitâb Maqâlat al-Asy'arî, dalam posisinya sebagai tokoh Sunnî, langsung menyusun daftar dan menganalisis kelompokkelompok Islam "sempalan," seperti Khawârij, Zaidiyah, al-Ghulât, Rawâfid, Mu'tazilah, dan Murji'ah, maka dalam Kitâb al-Ibânah ia menyusun tema-tema pokok yang menjadi bahan perselisihan di dalam ilmu kalam. Nampaknya, Kitâb al-Ibânah merupakan komplemen terhadap Kitâb Maqâlat.

Karya lainnya adalah milik Abû Mansûr 'Abd al-Kâhir b. Tâhir al-Baghdâdî (w. 1037), al-Farq Bayn al-Firaq (Skisme dan Sekte-sekte [dalam Islam]). Seperti al-Asy'arî, dalam bukunya ini alBaghdâdî juga mengulas doktrin dan paham yang berkembang dalam sekte-sekte Islam yang telah disebut sebelumnya. Pada periode berikutnya, Abû al-Muzhaffar Thâhir ibn Muhammad alIsfarâynî menulis Tabsîr fî̀ al-Dîn (Pencerahan tentang Agama). Dalam karyanya ini, alIshfarâynî tidak memberikan model sistematisasi maupun metodologi yang baru dari yang pernah ditulis al-Baghdâdî dalam menganalisis sektesekte Islam. Dari segi cakupan bahasan juga tidak ada perbedaan yang mencolok. Hanya saja, al-Isfarâynî menyertakan satu diskusi tentang

al-Mishriyyah, 1969-70). Versi lain dari naskah ini hanya menjudulkan Maqâlat al-Islâmiyyîn. Lihat juga Helga Brentjes (penerj.), Die Imamatslehren im Islam Nach Der Darstellung Des Asch'arî (Berlin: Akademie-Verlag, 1964).

${ }^{47}$ al-'Asy'arî, al-Ibânah 'an al-Ushul al-Dayânah, taqdîm watahqị̂ wa-ta'lîq Fawqiyyah Husayn Mahmûd, (Beirut: Dâr al-Kutub al-'Ilmiyyah); juga lihat The Elucidation of Islâm's Foundation: diterjemahkan dengan kata pengantar dan catatan oleh Walter C. Klein (New Haven, Conn.: American Oriental Society, 1940). kaum atheis (mulhidûn), selain memperjelas komitmennya sebagai penganut Sunni melalui pembahasan paham ahl- al-Sunnah wa al-Jamâ'ah di akhir pembahasan.

Al-Asy'arî, al-Baghdâdî, dan al-Isfarâynî adalah heresiograf awal yang merepresentasikan penulis-penulis Muslim Sunni, yang corak kajiannya sangat kental dengan judgment teologis terhadap kelompok-kelompok non-mainstream. Al-Baghdâdî memberikan klasifikasi tersendiri tentang apa yang disebut dengan mazhab "sesat" atau "menyesatkan." Dia menilai bahwa perbedaan dalam bidang furu' yang menyebabkan munculnya mazhab-mazhab fiqih, masih dapat ditolerir selama mereka, para penganut mazhabmazhab fiqih itu, masih dapat bersepakat dalam hal dasar-dasar agama (ushûl al-dîn). Sebaliknya, terdapat "kelompok terlarang" (al-farq almadzmûmah) atau "penganut sekte yang sesat" (ashhâb al-ahwa' al-dhâllah), yakni mereka yang berbeda pendapat dari ahl al-sunnah wa al-jamâ'ah dalam hal teologis. Konsep "sesat" tersebut dia tujukan kepada sekte-sekte yang terdapat dalam bukunya. ${ }^{48}$ Prinsip yang sama juga dipegang oleh al-Isfarâynî yang tujuan penulisan bukunya adalah untuk mengidentifikasi sekte "sesat" (alfarq al-dhâllah) dan membedakan agamanya dari agama-agama lain "yang menyesatkan" ('an adyânihim al-dhâllah). ${ }^{49}$

Karya para heresiograf Muslim tersebut setidak-tidaknya menjadi dasar bagi para heresiograf generasi berikutnya, seperti Ibn Hazm melalui Kitâbal-Fishl dan al-Syahrastânî yang menulis Kitâbal-Milal. Berbeda dengan ketiga heresiograf sebelumnya yang "Sunni murni," Ibn Hazm sendiri dikenal sebagai penganut mazhab Dzâhirî (literalis-eksternalis), sedangkan al-Syahrastânî adalah teolog dan filsuf besar Asy'ariyah yang "dicurigai" menganut atau setidaknya bersimpati kepada 'Ismâ'îliyah. Sementara al-Bîrûnî tidak menelurkan karya

\footnotetext{
48al-Baghdâdî, al-Farq bain al-Firaq, 26; Muslim Schisms and Sects, 23.

${ }^{49}$ al-Isfarâynî, Tabsîr fî al-Dîn, 10-11.
} 
heresiografi secara khusus, ia bahkan lebih dikenal sebagai seorang ilmuwan di bidang geografi, matematika, dan sejarah ketimbang sebagai heresiograf. Faktor-faktor inilah yang membedakan mereka dengan para sejarahwan, penulis, dan teolog Muslim sebelumnya.

\section{Kesimpulan}

Kebanyakan persepsi, cara pandang, dan bahkan metodologi yang digunakan kaum Muslim dalam mencermati agama dan sekte agaknya tidak bisa dilepaskan dari teori dan cara pandang yang telah berkembang sejak abad pertengahan Islam ketika agama-agama dan sekte-sekte menjadi salah satu isu sentral. Meskipun demikian, berdasarkan pada observasi awal di atas, karya-karya Muslim tersebut tidak melulu dilatarbelakangi oleh motif yang sama. Setidaknya sebagian menulis tentang agama-agama dan sekte-sekte sebagai bagian dari catatan perjalanan para pedagang maupun pengembara, sehingga perspektif yang dibangun ketika menganalisa agama-agama di luar Islam tersebut tidak semata-mata teologis. Sementara itu, sebagian lainnya memang ditulis khusus untuk mengupas agama-agama dan sekte-sekte yang ada, dan ditujukan untuk mengoreksi atau mengritik banyak hal, terutama pada sisi teologis.

Bila kita cermati lebih jauh, dan tentu harus diteruskan dengan penelaahan dan penelitian lanjutan, cara pandang kaum Muslim tersebut mengerucut pada dua kutub yang sampai saat ini masih belum dapat disatukan sepenuhnya, yakni kutub yang bercorak deskriptif-analitik, dan kutub lainnya yang bersifat teologis-polemis. Deskripsi di atas setidaknya sudah memetakan bagaimana manifestasi kedua kutub tersebut dalam studi agama dan sekte. Artinya, konsepkonsep teoretis tentang bagaimana kaum Muslim mempersepsikan agama-agama lain dapat ditemukan dalam karya-karya Muslim klasik.

Sebagai catatan akhir dari survei awal terhadap literatur Muslim Abad Pertengahan tentang agama dan sekte adalah, apa konsekuensikonsekuensi dari karya-karya heresiografi dan ilmu perbandingan agama yang ditulis pada Abad Pertengahan bagi kaum Muslim di era modern? Catatan penulis sementara ini adalah bahwa munculnya hereiograf Muslim tidaklah terhenti pada era tersebut, melainkan di era modernpun akan senantiasa muncul sekte-sekte baru dan bahkan agama-agama baru yang kemudian disusul oleh munculnya heresiograf-heresiograf baru, baik dalam bentuk personal maupun kelembagaan. Dewasa ini, tidak jarang respons negatif dan bahkan 'represif' dengan melibatkan tindak kekerasan dari kelompok-kelompok keagamaan arus utama terhadap sekte-sekte atau aliran keagamaan yang dianggap "sesat." Dan itu semua adalah salah satu bentuk konsekuensi dari teori dan praktik heresiografi yang dianut oleh masyarakat saat ini.

\section{Daftar Kepustakaan}

Adang, Camilla. Muslim Writers on Judaism and The Hebrew Bible: From Ibn Rabban to Ibn Hazm. Leiden, New York, and Koln: E.J. Brill, 1996.

Ahmad, S. Maqbul. Indo-Arab Relations: An Account of India's Relations with the Arab World from Ancient up to Modern Times. New Delhi: Indian Council for Cultural Relations; Bombay: Popular Prakashan, 1969.

Ahmad, S. Maqbul. Arabic Classical Accounts of India and China. Calcutta: Indian Institute of Advance Studies, 1989.

al-'Asy'arî. The Elucidation of Islâm's Foundation: diterjemahkan dengan kata pengantar dan catatan oleh Walter C. Klein. New Haven, Conn.: American Oriental Society, 1940.

al-Baghdâdî, Abû Mansûr. al-Farq bain al-Firaq wa Bayân al-Firqah al-Nâjiyah Minhum: ‘Aqâid al-Firq al-Islâmiyyah wa Ārâ Kibâr 
A'lâmahâ. Cairo: Maktabah Ibn Sînâ li al-Nashr wa al-Tauzî’ wa al-Tashdîr, t.t.

al-Mas'ûdî. Murûj al-Dzahab wa Ma'âdin alJauhar. Beirut: Makshûrât al-Jâmi'ah alLibâniyah, 1966.

al-Mas'ûdî. Meadows of Gold and Mines of Gems, diterjemahkan oleh Aloys Springer. London: Printed oleh the Oriental Translation Fund of Great Britain and Ireland, 1841.

al-Qasim Abû. Al-Masâlik wa al-Mamâlik. Damascus: Manshûrât wa Zârat alThaqâfah,1989.

al-Sirâfî, Sulaymân al-Tâjir dan Abî Zayd Hasan. Akhbâr al-Sîn wa al-Hind, tahqîq Yûsuf al-Syârûnî. al-Qâhirah: al-Dâr alMishriyyah al-Banâniyah, 1999.

al-Tawânisî. Abû al-Futûh Muhammad. Abû Rayhân Muhammad b. Aḥmad al-Bîrûnî: al-'Ālim al-Falakî, al-Jiyâlûjî,wa alRiyâdhi al-Mu'arrikh Mutarajim Tsaqâfah al-Hind. Muassasah Dâr al-Tahrîr li Thab'i wa al-Nashr, 1968.

al-Thabarî, Abû Ja'far Muhammad b. Jarîr. The History of al-Thabarî (Ta'rîkh al-Rusul wa al-Mulûk [diterjemahkan and dianotasi oleh Franz Rosenthal]. Vol. I. Albany: State University of New York Press, 1989.

Arnold, T.W. The Preaching of Islam: A History of the Propagation of the Muslim Faith. Lahore: Kasymiri Bazar, 1961.

Brentjes Helga (penerj.) Die Imamatslehren im Islam Nach Der Darstellung Des Asch'arî. Berlin: Akademie-Verlag, 1964.

Freidmann, Yohanan. "Medieval Muslim views of Indian Religions." Journal of the American Oriental Society 95 (1975).

Gutas, Dimitri. Greek Thought, Arabic Culture: The Graeco-Arabic Translation Movement in Baghdad and Early 'Abbâsid Society $\left[2^{\text {nd }}-4^{\text {th }} / 8^{\text {th }}-10^{\text {th }}\right.$ centuries $]$. London: Routledge.

Hodgson, Marsyall G. S. The Venture of Islam, Volume 1; The Classical Age of Islam. Chicago \& London: The University of Chicago Press, 1974.

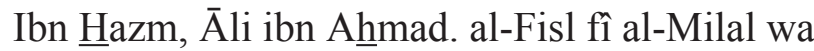
Ahwâ wa al-Nihal, tahqiq Muhammad Ibrâhîm Nashr and Abûdurrahman Umayrah. Jeddah: Syairkah Maktabah Ukad, 1982.

Jahn, Karl. Rashîd al-Dîn's History of India: Collected Essays with Facsimiles and Indice. London \& Paris: The Hague, Mouton \& CO

Jeffery, A. "Al-Bîrûnî's Contribution to Comparative Religion.” Dalam Al-Bîrûnî: Commemoration Volume. Calcutta: Iran Society, 1951.

K.A. Mubârakpâri. al-'Arab wa al-Hind fî 'ahd al-Risâlah.Diterjemahkan oleh Abd alAziz 'Izzat 'Abd al-Jalil], al-Qahirah: al-Haiah al-Mishriyyah al-'Ammah li al-Kitâb,1973.

K.A. Mubârakpâri. al-Hind fî 'Ahd al-'Abbâsiyyîn. al-Qâhirah: Dâr al-Anshar,1980.

Khalidi, Tarif. Classical Arab Islam: The Culture and Heritage of the Golden Age. New Jersey, Princeton: Darwin Press, 1985.

Khan, M.A. Saleem. Early Muslim Perception of India and Hinduism. New Delhi: South Asian Publishers, 1997.

Knysh, Alexander. "'Orthodoxy' and 'Heresy' in Medieval Islam: An Essay in Reassessment." The Muslim World LXXXIII, no. 1 (1993).

Luthfi Assyaukanie. "Tipologi dan Wacana Pemikiran Arab Kontemporer." Jurnal Pemikiran Islam Paramadina I, no. 1 (1998). 
Madelung, Wilfred. The Succession to Muhammad. Cambridge: Cambridge University Press.

Pulcini, Theodore. Exegesis as Polemical Discourse: Ibn Hazm on Jewisy and Christian Scriptures. Atlanta, Georgia: Scholars Press, 1998.

Rahman, Fazlur. Prophecy in Islam: Philosophical Doctrines and the Orthodoxy. London: George Allen \& Unwin Ltd, 1958.

Syarpe, Eric J. Comparative Religion: A History. Illinois: La Salle: Open Court, 1991.
Waardenburg, Jaques. Muslim Perception of Other Religions: A Historical Survey. New York: Oxford University Press, 1999.

Watt, Montgomery. Islamic Theology and Philosophy. Edinburg: Edinburg University Press, 1987.

Wink, Andre. Al-Hind: The Making of the IndoIslamic World: Volume I: Early Medieval India and the Expansion of Islam 7-11 Centuries. Leiden, New York, Köln: Brill, 1997. 